\title{
EBV-Associated T-Cell Lymphoproliferative Diseases in Young Adults with Unusual Histopathological and Immunophenotypic Features
}

\author{
Mingyang Li \\ Department of Pathology and Pathophysiology, Fourth Military Medical University, Xi'an, China \\ Email: limingyang1108@sina.com
}

How to cite this paper: Li, M.Y. (2017) EBV-Associated T-Cell Lymphoproliferative Diseases in Young Adults with Unusual Histopathological and Immunophenotypic Features. Open Access Library Journal, 4: e3951.

https://doi.org/10.4236/oalib.1103951

Received: September 19, 2017

Accepted: October 9, 2017

Published: October 12, 2017

Copyright ( 2017 by author and Open Access Library Inc.

This work is licensed under the Creative Commons Attribution International License (CC BY 4.0).

http://creativecommons.org/licenses/by/4.0/

\begin{abstract}
EBV-associated T-cell lymphoproliferative diseases (EBV ${ }^{+} \mathrm{T}$-cell LPDs) in non-immunocompromised hosts are a heterogenous syndrome which is challengeable for both diagnosis and treatment. Here, we report four young patients of $\mathrm{EBV}^{+} \mathrm{T}$-cell LPDs with unusual histopathological and immunophenotypic features. They presented with intermittent high fever (4/4), multiple lymphadenopathy (4/4), hepatosplenomegaly (4/4), hematochezia (2/4) and high blood EBV antibodies titer (4/4) for seven months to one year. The enteroscopic examination revealed multiple ileocecus ulcers in three of four cases. Histologically, three cases showed similar dense infiltration of polymorphic composition including variable reactive components such as plasma cells and histiocytes as well as atypical lymphocytes and one case was characterized by proliferation of monomorphic atypical lymphocytes. The infiltrating lymphocytes were medium-sized with hyperchromatic nuclei and showed mild cytologic atypia. Abundant eosinophils infiltration and formation of eosinophilic abscess were seen in all cases. Multiple foci of necrosis with granuloma were observed in lymph nodes of all cases, but hemophagocytosis was absent. The immunohistochemical staining showed that infiltrative lymphocytes were $\mathrm{CD}^{+}{ }^{+} \mathrm{TIA}^{+} \mathrm{CD}^{-} 6^{-}$, suggesting cytotoxic $\mathrm{T}$-cells origin, but loss of pan- $\mathrm{T}$ markers CD3 (2/4), CD5 (4/4) and CD7 (2/4) were frequently observed. Negativity for both CD4 and CD8 (4/4) and silent T-cell receptor (TCR) expression (3/3) were detected. EBV positivity in numerous T-cells was identified by double staining of $\mathrm{CD} 3$ and EBER. Three patients died within one year and one patient is alive six months after initial presentation. These unusual pathologic findings prompt us being aware of $\mathrm{EBV}^{+} \mathrm{T}$-cell LPDs and add to the understanding of this rare disease.
\end{abstract}




\section{Subject Areas}

Pathology

\section{Keywords}

EBV-Associated T-Cell Lymphoproliferative Diseases,

Chronic Active EBV Infection, Eosinophilic Abscess, Granuloma

\section{Introduction}

Epstein-Barr virus (EBV) is a ubiquitous virus that can cause both acute and chronic active infections [1]. Over $90 \%$ of humans are infected with EBV and the infection persists for life. It is usually asymptomatic following the primary infection in normal hosts because EBV-specific immunity, especially EBV-specific cytotoxic T lymphocytes (CTL), controls the infection during the long-term carrier state [2]. However, in some apparently immunocompetent hosts, it progresses to chronic active infection. Chronic active EBV infection (CAEBV) was first described by Virelizier et al. in 1978 [3] and was characterized by chronic or recurrent infectious mononucleosis-like symptoms persisting for at least 6 months, and associated with high blood EBV antibodies titer without association to malignancy, autoimmune diseases or immunodeficiency [4].

CAEBV is found to be prevalent in Asian countries and characterized by proliferation of the EBV-infected T/NK cells which is related with EBV-associated T/NK-cell lymphoproliferative disorders $\left(\mathrm{EBV}^{+} \mathrm{T} / \mathrm{NK}-\mathrm{LPDs}\right)$ [5], however, CAEBV is mostly associated with EBV-infected B cells in Western countries [6]. CAEBV of T/NK type shows a broad range of clinical manifestations from indolent, localized forms to a more systemic, aggressive form with the types of the infected cells clonality ranging from polyclonal to monoclonal, which are different from case to case, as do the prognoses [7] [8]. According to the 4th edition of World Health Organization (WHO) classification of tumors of hematopoietic and lymphoid tissues in 2008 [9], two major types of EBV-positive T-cell LPDs of childhood have been described including hydroa vacciniforme-like lymphoma, a cutaneous malignancy with an indolent course, and systemic EBV-positive T-cell LPD of childhood which has a very aggressive and fulminant clinical course. A more severe form of CAEBV [10] characterized by high fever, hepatosplenomegaly, extensive lymphadenopathy and pancytopenia frequently with monoclonal $\mathrm{EBV}^{+} \mathrm{T}$-cell proliferation represents part of the spectrum of systemic EBV-positive T-cell LPD of childhood.

Because of its rarity and complexity, it is necessary to find more pathological information of $\mathrm{EBV}^{+} \mathrm{T}$-cell LPDs in favour of diagnosis and treatment. In this study, we report four cases of $\mathrm{EBV}^{+} \mathrm{T}$-cell LPDs with unusual immunophentypic and histopathological features including negativity for CD4 and CD8, multiple foci of necrosis, abundant eosinophils inflitration and granuloma, which adds to the understanding of these rare diseases. 


\section{Materials and Methods}

Formalin-fixed, paraffin-embedded tissue blocks of intestine and lymph node biopsies were available for evaluation. Clinical and laboratory information was obtained from the medical records, the referring pathologists, and the clinicians. The diagnosis of CAEBV was defined according to previously proposed criteria [11] and $\mathrm{EBV}^{+} \mathrm{T}$-cell LPDs was categorized by the criteria of Ohshima $\mathrm{K}$ et al. [12]. Institutional ethical approval was obtained in compliance with the Helsinki Declaration.

\subsection{Immunophenotypic Studies}

Immunohistochemistry (IHC) was performed using formalin-fixed, paraffin embedded tissue sections on a Bond-III Autostainer (Leica Biosystems, Melbourne, Australia) according to the company's protocol with slight modifications. The antibody panel included CD2, CD3, CD5, CD8, CD20 (all from MXB Biotechnologies, Fuzhou, Fujian, China), CD4, CD56, Ki-67 (all from Dako, Copenhagen, Denmark), TIA-1, CD7 (all from Gene Tech Company Limited, Shanghai, China), TCR- $\beta$ F1 and TCR-c $\gamma M 1$ (all from Thermo Scientific, Rockford, IL, USA). Appropriate positive and negative tissue controls were used for these studies.

\subsection{In Situ Hybridization for EBV}

The presence of EBV was examined by in situ hybridization (ISH). Epstein Barr-encoded RNA-in situ hybridization (EBER-ISH) was performed using the Bond-Max Autostainer (Leica Biosystems, Melbourne, Australia) with ISH kits for EBV (Leica Biosystems, Newcastle Upon Tyne, UK) following manufacturer's instructions. Double staining for EBER-ISH and CD3 or CD20 immunohistochemistry were performed following the above-described methods.

\subsection{TCR Gene Rearrangement Assay}

Genomic DNA of intestine lesions and lymph nodes was isolated using QIAamp FFPE Tissue Kit (Qiagen, Germantown, MD, USA) and was amplified by polymerase chain reaction (PCR) according to the BIOMED-2 clonality assays. TCR gene clonality including TCR $\beta$ and $\gamma$ gene was determined by multiplex PCR using the BIOMED-2 multiplex PCR kits (Yuan Qi Biomed, Shanghai, China) according to the standard BIOMED-2 multiplex PCR protocol and PCR primer sets as previously described [13]. Each reaction included monoclonal and polyclonal control. The fluorescently labeled PCR products were detected and interpreted by capillary gel electrophoresis using the ABI 3500 Dx Genetic Analyzer (Applied Biosystems, Foster City, CA, USA) according to the manufacturer's instructions.

\section{Results}

\subsection{Clinical Characteristics, Treatments and Outcomes}

The clinical features of the patients are summarized in Table 1. There were two 
Table 1. Clinical characteristics, treatments and outcomes of 4 cases with $\mathrm{EBV}^{+} \mathrm{T}$-cell LPDs.

\begin{tabular}{|c|c|c|c|c|c|c|c|}
\hline \multirow{2}{*}{$\begin{array}{l}\text { Case } \\
\text { no. }\end{array}$} & \multirow{2}{*}{ Sex } & \multirow{2}{*}{$\begin{array}{l}\text { Age } \\
\text { (Year) }\end{array}$} & \multirow{2}{*}{ Clinical presentation } & \multicolumn{2}{|c|}{ EBV serology } & \multirow{2}{*}{ Treatment } & \multirow{2}{*}{$\begin{array}{l}\text { Outcome } \\
\text { (months) }\end{array}$} \\
\hline & & & & anti-VCA IgG & anti-VCA IgM & & \\
\hline 1 & M & 22 & $\begin{array}{l}\text { Intermittent high fever, abdominal pain and } \\
\text { hematochezia for } 8 \text { months; pancytopenia, } \\
\text { bnormal liver function tests, multiple } \\
\text { mesenteric lymphadenopathy, } \\
\text { hepatosplenomegaly, multiple ileocecus ulcers }\end{array}$ & Positive & Positive & $\begin{array}{l}\text { Supportive } \\
\text { therapy, } \\
\text { antibiotics } \\
\text { and surgery }\end{array}$ & DOD (12) \\
\hline 2 & $\mathrm{~F}$ & 23 & $\begin{array}{l}\text { Repeated fever and abdominal pain for } 10 \text { months; } \\
\text { multiple lymphadenopathy (bilateral neck, axillary, } \\
\text { groin), hepatosplenomegaly, multiple ileocecus ulcers }\end{array}$ & Positive & NA & $\begin{array}{l}\text { Supportive } \\
\text { therapy } \\
\text { and surgery }\end{array}$ & DOD (12) \\
\hline 3 & $\mathrm{~F}$ & 18 & $\begin{array}{l}\text { Repeated fever, abdominal pain and } \\
\text { hematochezia for } 1 \text { year; multiple lymphadenopathy } \\
\text { (left neck, mediastinal, retroperitoneal, mesenteric), } \\
\text { hepatosplenomegaly, multiple ileocecus ulcers }\end{array}$ & Positive & NA & $\begin{array}{l}\text { Surgical } \\
\text { resection } \\
\text { of the } \\
\text { lesional } \\
\text { intestine }\end{array}$ & DOD (1) \\
\hline 4 & M & 14 & $\begin{array}{l}\text { Intermittent high fever, purpura and weight loss for } 7 \\
\text { months; pancytopenia, abnormal liver function tests, } \\
\text { multiple lymphadenopathy (bilateral neck,axillary, } \\
\text { mediastinal, retroperitoneal), hepatosplenomegaly }\end{array}$ & Positive & Negative & Chemotherapy & $\operatorname{AWD}(6)$ \\
\hline
\end{tabular}

VCA, viral capsid antigen; $M$, male; F, female; NA, not available; DOD, dead of disease; AWD, alive with disease.

males and two females with ages ranging from 14 to 23 years (median age, 20 years). All cases were Chinese without opportunistic infections or other indications of any congenital immunodeficiency, nor had they received immunosuppressive medications. All four patients presented with long term intermittent high fever, multiple lymphadenopathy and hepatosplenomegaly for seven months to one year. The other clinical symptoms and signs including hematochezia (2/4), abdominal pain (3/4), and multiple intestinal ulcers (3/4) were also observed. Symptoms like weight loss and purpura were also found. One patient (case 1) had elevated lactate dehydrogenase (LDH) levels (745 IU/L) and two patients (case 1 and case 4) had pancytopenia and abnormal liver function tests. No patient was associated with hemophagocytosis. All four patients showed positive EBV antiviral capsid antigen (anti-VCA) IgG titers with positive or abscent anti-VCA IgM antibodies. Antibodies to hepatitis viruses and cytomegalo virus were negative in all patients. As with the treatments and outcomes of our cases, two patients had only supportive therapy and surgery and died 1 year after presentation. One patient died of postoperative complications after surgical resection of the lesional intestine and the other received chemotherapy and remained in stable disease for six months.

\subsection{Histopathologic Findings}

Three cases (cases 1 - 3) showed essentially similar histologic findings in the intestine. The intestinal epithelial cells were markedly eroded with ulcers and dense infiltration of atypical lymphocytes intermingled with abundant eosinophils in 
the mucosa and submucosa (Figure 1(a)). The infiltrating lymphocytes were medium-sized with mild cytologic atypia and showed a high nucleus to cytoplasm ratio with slightly irregular hyperchromatic nuclei and thick nuclear membrane, mitoses were rare (Figure 1(b)). Variable amount of reactive components such as plasma cells and histiocytes were also observed in the background. However, case 3 was characterized by proliferation of monomorphic atypical lymphocytes without polymorphic cellular composition (Figure 1(c)). Mucosa adjacent to the ulcers displayed prominent proliferation of lymphoid tissue with reactive germinal center of lymphoid follicles and infiltration of large amount of eosinophils.

The normal architecture of lymph nodes was markedly distorted in all four cases. Multiple foci of necrosis were observed in each case and the necrosis was surrounded by epithelioid cells with granuloma (Figure 1(d)). The residual lymph node tissue around necrosis was infiltrated by atypical lymphocytes as described above and an abundant of eosinophils. Furthermore, eosinophilic abscess was observed occasionally in lymph node of each case (Figure 1(e)) and angiocentric infiltration of atypical lymphocytes was identified (Figure 1(f)). Hemophagocytosis was absent in all cases.

\subsection{Immunophenotypic Findings and Genetic Studies}

The immunophenotypic and genetic features of the cases are summarized in Table 2. Immunohistochemical staining was performed on the intestine and lymph node in all cases. The infiltrative lymphocytes were composed predominantly of CD2 ${ }^{+} \mathrm{CD} 20^{-} \mathrm{CD}^{-} 6^{-} \mathrm{T}$ cells in all cases (Figures $2(\mathrm{a})-(\mathrm{c})$ ). Loss of pan-T

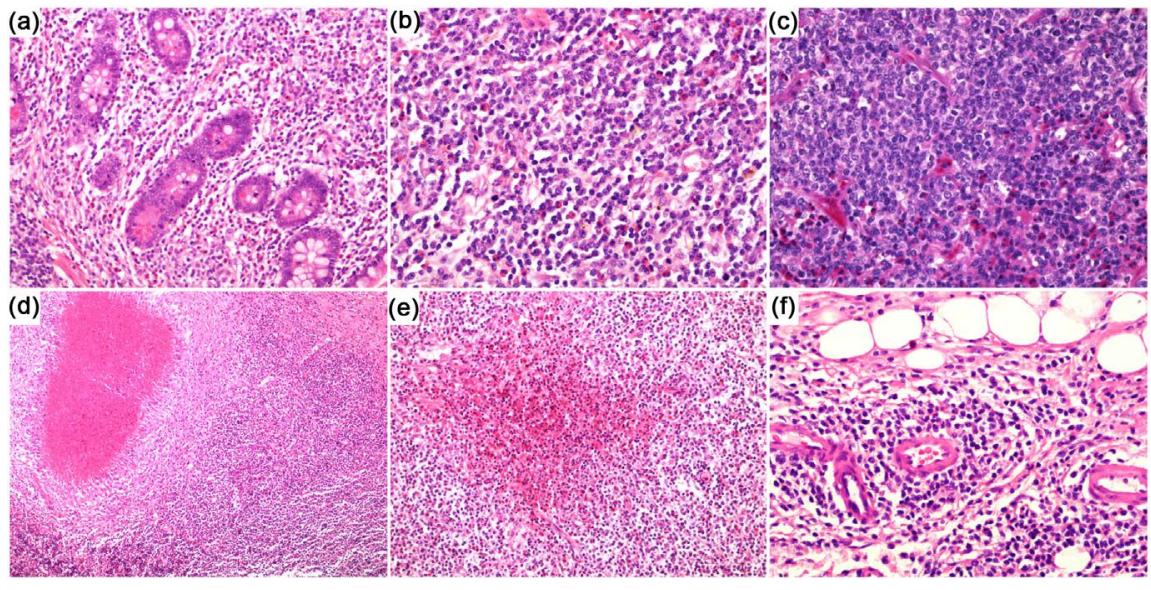

Figure 1. Histologic findings in intestine and lymph node. (a) Intestine specimen from case 1 showed infiltration of atypical lymphocytes intermingled with abundant eosinophils in the mucosa and submucosa ( $\mathrm{H} \& \mathrm{E}, \times 200)$; (b) The infiltrating lymphocytes were medium-sized with mild cytologic atypia and reactive components were observed in the background (H \& E, $\times 400)$; (c) Case 3 was characterized by proliferation of monomorphic atypical lymphocytes without polymorphic cellular composition (H \& E, × 400); (d) Granuloma (H\&E, $\times 100)$; (e) eosinophilic abscess (H \& E, $\times 200)$ and (f) angiocentric infiltrationof atypical lymphocytes $(\mathrm{H} \& \mathrm{E}, \times 400)$ were identified in lymph node from case 1. 
Table 2. Immunophenotypic and genetic features of 4 cases with $\mathrm{EBV}^{+} \mathrm{T}$-cell LPDs.

\begin{tabular}{|c|c|c|c|c|c|c|c|c|c|c|c|c|c|}
\hline \multicolumn{14}{|c|}{ Immunophenotype } \\
\hline Case no. & $\mathrm{CD} 2$ & $\mathrm{CD} 3$ & CD5 & CD7 & $\mathrm{CD} 4$ & CD8 & CD56 & $\mathrm{CD} 20$ & TIA-1 & TCR- $\beta \mathrm{F} 1$ & TCR-c $\gamma \mathrm{M} 1$ & EBER & $\begin{array}{c}T C R \text { gene } \\
\text { rearrangements }\end{array}$ \\
\hline 1 & + & + & - & + & - & - & - & - & + & - & - & + & Polyclonal \\
\hline 2 & + & - & - & - & - & - & - & - & + & - & - & + & Polyclonal \\
\hline 3 & + & - & - & + & - & - & - & - & + & - & - & + & $\begin{array}{l}T C R-\gamma \text { gene } \\
\text { monoclonal }\end{array}$ \\
\hline 4 & + & + & - & - & - & - & - & - & + & NA & NA & + & $\begin{array}{l}\text { TCR- } \gamma \text { gene } \\
\text { monoclonal }\end{array}$ \\
\hline
\end{tabular}

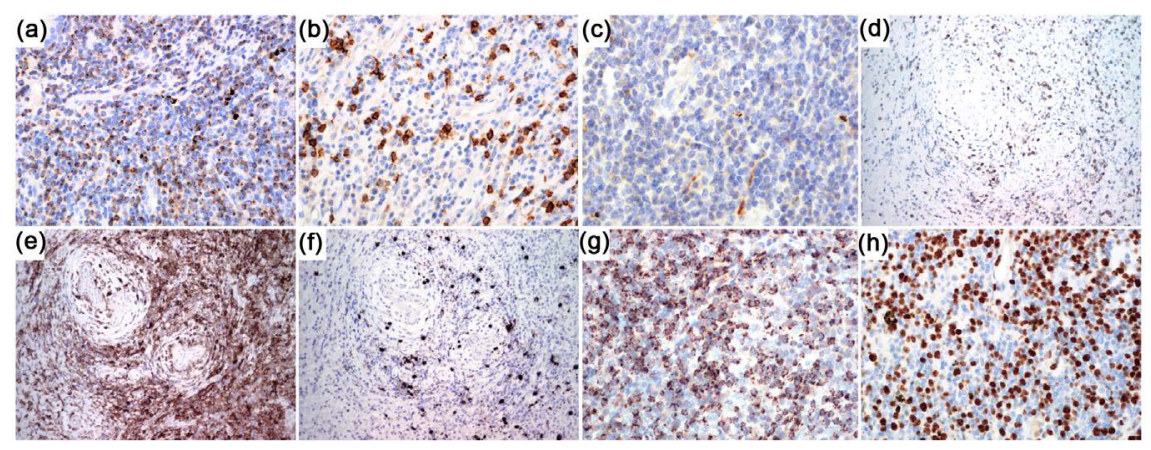

Figure 2. Immunophenotypic findings from case 2. The infiltrative lymphocytes were predominantly (a) $\mathrm{CD}^{2+}$; (b) CD20; (c) CD56-T cells $(\times 400)$. Loss of pan-T markers (d) CD3 was observed and most of the atypical lymphocytes showed loss of (e) CD4 antigen and (f) CD8 antigen $(\times 200)$; (e) Staining for CD4 highlighted histiocytes, whereas the lymphocytes are negative; (g) The atypical lymphocytes were TIA-1 positive (h) with high Ki-67 index.

markers including CD3 (2/4) (Figure 2(d)), CD5 (4/4) or CD7 (2/4) was observed and most of the lymphocytes showed loss of CD4 and CD8 antigen in all four cases unexpectedly (Figure 2(e) and Figure 2(f)). TCR $\beta$ and TCR $\gamma$ were negative in 3 cases indentified by TCR $\beta F 1$ and TCR $c \gamma M 1$ antibodies. The infiltrative lymphocytes were TIA-1 positive (Figure $2(\mathrm{~g})$ ) with high Ki-67 index in all cases (Figure $2(\mathrm{~h})$ ). The immunophenotype demonstrated that the infiltrative lymphocytes were mainly cytotoxic T-cells. EBER-ISH showed striking positivity in the large number of lymphocytes in all cases (Figure 3(a)). Correlation of the EBV positivity with the distribution of $\mathrm{CD} 3$ or $\mathrm{CD} 20$ staining clearly indicated the presence of EBER in the $\mathrm{CD}^{+} \mathrm{T}$-cells (Figure 3(b)), while the $\mathrm{CD} 20^{+}$ B-cells were clearly negative (Figure $3(\mathrm{c})$ ). Analysis by PCR of paraffin-embedded tissue from the lymph nodes showed clonal rearrangements of the TCR- $\gamma$ genes in case 3 and 4 (Figure 4), and the other two cases showed a polyclonal pattern of $T C R$ gene.

\section{Discussion}

We report four cases of $\mathrm{EBV}^{+} \mathrm{T}$-cell LPDs in adolescents and young adults with unusual histopathological and immunophenotypic features. Three patients 


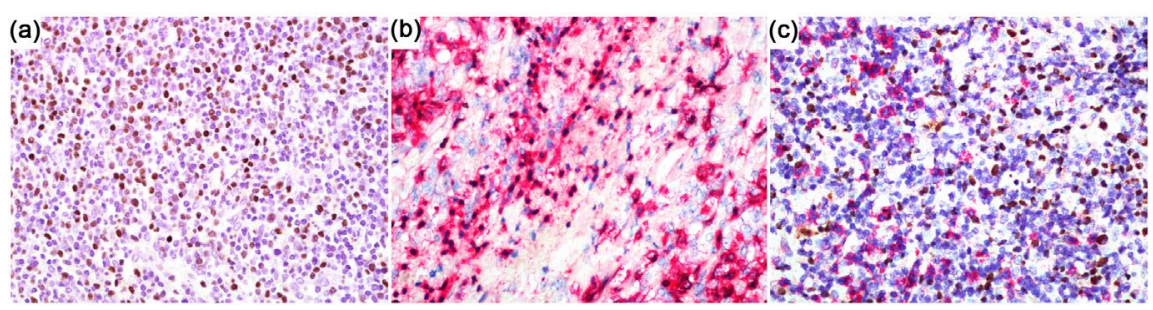

Figure 3. EBER in situ hybridization and double staining for CD3/EBER and CD20/EBER from case 4. (a) EBER in situ hybridization showed striking positivity in the large number of atypical lymphocytes. Double staining showed that (b) the $\mathrm{CD}^{+} \mathrm{T}$-cells harbored the EBV, whereas (c) CD20 $0^{+}$-cells were clearly negative $(\times 400)$.

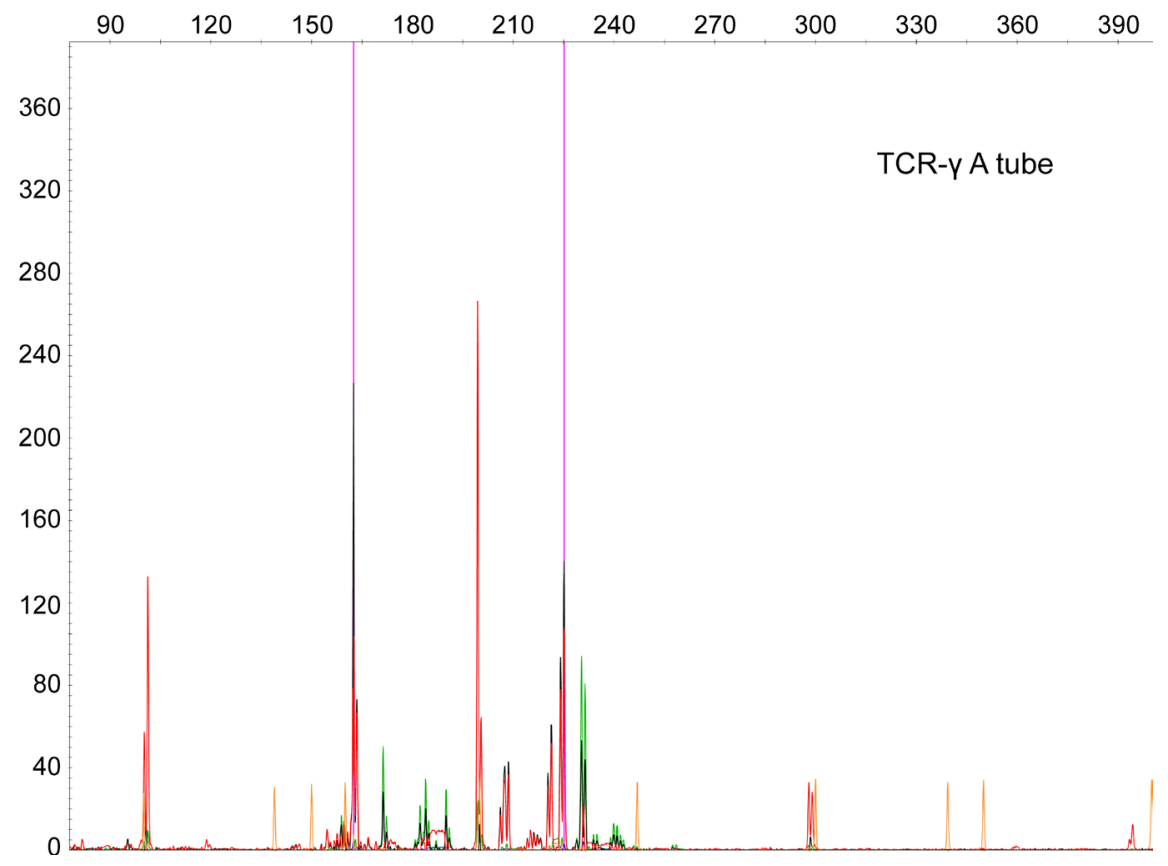

Figure 4. TCR gene rearrangement assay from case 4 . The TCR gene rearrangement assay by using a BIOMED-2 multiplex PCR protocol showed a monoclonal peak of TCR- $\gamma$ gene.

showed aggressive clinical course and died within one year after the initial presentation and one case remained in stable disease for six months. Because of the complicated clinical and histopathological presentation and lacking characteristic morphologic changes, diagnosis should be made with combined information including clinical symptoms and signs, laboratory examinations and pathological findings instead on the basis of morphology alone. Based on the diagnostic criteria of $\mathrm{EBV}^{+} \mathrm{T}$-cell LPDs, our cases satisfied the diagnosis of $\mathrm{EBV}^{+} \mathrm{T}$-cell LPDs for the following reasons. Firstly, all patients experienced typical infectious mononucleosis (IM)-like symptoms for at least six months including persistent high fever, multiple lymphadenopathy, hepatosplenomegaly and even hematochezia or multiple intestinal ulcers with a high blood EBV antibody titers. Moreover, numerous medium-sized atypical lymphocytes positive for EBER infiltrated the intestine and lymph node. The histopathologic features including 
multiple foci of necrosis, granuloma, abundant eosinophils infiltration and even the formation of eosinophilic abscess were unusual in $\mathrm{EBV}^{+} \mathrm{T}$-cell LPDs. The infiltrative atypical lymphocytes were $\mathrm{CD} 2^{+} \mathrm{TIA}^{+} \mathrm{T}$ cells, whereas double negativity for CD4 and CD8 and silent TCR expression were also uncommon in this rare disease.

Many cases of $\mathrm{EBV}^{+} \mathrm{T}$-cell LPDs clinically overlap with CAEBV and fulminant $\mathrm{EBV}^{+} \mathrm{T}$-cell LPD of childhood which was first identified by Su et al. in 1990 [14]. An international meeting organized at the National Institutes of Health in Bethesda [15] confirmed $\mathrm{EBV}^{+} \mathrm{T} / \mathrm{NK}$-LPDs encompass a very broad spectrum of diseases that have excessive lymphoid proliferation of mainly T/NK cells as a common characteristic in non-immunocompromised hosts with different pathological findings and clinical courses. Ohshima $\mathrm{K}$ et al. [12] presented a proposed categorization of $\mathrm{EBV}^{+} \mathrm{T} / \mathrm{NK}-\mathrm{LPD}$ according to the clinical and pathological features. They divided cases into four categories: category A1 (polymorphic LPD without clonal proliferation of EBV-infected cells), category A2 (polymorphic LPD with clonal proliferation of EBV-infected cells), category A3 (monomorphic LPD with clonal proliferation of EBV-infected cells) and category B (monomorphic LPD with clonal proliferation of EBV-infected cells and fulminant clinical course from an apparent primary EBV infection). Categories A1-A3 were equivalent to CAEBV, while category $B$ was defined as equivalent to fulminant $\mathrm{EBV}^{+} \mathrm{T}$-cell LPD of childhood. The proposed categorization suggested that $\mathrm{EBV}^{+} \mathrm{T} / \mathrm{NK}$-LPDs develop from polyclones or oligoclones and subsequently expand as monoclones to cause aggressive clinical outcomes. According to the proposed categorization, case 1 and 2 in our study were classified into A1 category because of polymorphic cellular composition including small mature lymphocytes, histiocytes, plasma cells as well as the EBV-infected T cells without clonal proliferation. Likewise, case 4 fell into category A2 for polymorphic infiltration with clonal rearrangements of TCR gene and case 3 was classified into category A3 for monomorphic infiltration with clonal proliferation. Category A1 and A2 corresponding to smoldering state and chronic state, respectively [8] whose 5 years overall survival (OS) rate is $70 \%$ showed better prognosis than category A3 whose 5 years OS rate is less than 30\% [16]. However, our two patients of category A1 who refused to receive further treatment and died within one year cannot objectively reflect the process of disease.

The most commonly involved sites of $\mathrm{EBV}^{+} \mathrm{T}$-cell LPDs are liver and spleen followed by lymph nodes, bone marrow, skin and lung [9], however, intestine involvement of our cases is very rare and noteworthy. Morphologically, EBV ${ }^{+}$ T-cell LPDs lack characteristic morphologic changes and are characterized by a wide-ranging features from reactive to atypic appearance [12]. In our study, three cases showed polymorphic cellular infiltration similar to reactive changes and one case showed monomorphic atypical lymphocytes infiltration with or without TCR gene rearrangements. Case 3 and 4 with monoclonal $\mathrm{EBV}^{+} \mathrm{T}$-cell proliferation overlap systemic EBV-positive T-cell LPD of childhood in the setting of CAEBV which are considered neoplasms in 2008 WHO classification of 
tumors of hematopoietic and lymphoid tissues [9]. More importantly, very unusual features of our cases containing multiple foci of necrosis, eosinophilic abscess and granuloma formation in $\mathrm{EBV}^{+} \mathrm{T}$-cell LPDs add to the understanding of the clinicopathological spectrum of these rare diseases.

The EBV-infected T-cells of cases secondary to acute primary EBV infection are unually $\mathrm{CD} 8^{+} \mathrm{T}$-cells, whereas cases in the setting of severe CAEBV are often CD4 ${ }^{+}$T-cells [9]. In our study, consistent expression of CD2 and TIA1 in the inflitrative lymphocytes suggested the cytotoxic T-cell origin of our four cases. However, unlike other studies where CD4 or CD8 is often alternatively positive in proliferative T-cells, negativity for both CD4 and CD8 was identified in our four cases. Moreover, loss of pan-T markers such as CD3, CD5 and CD7 and TCR expression was also found in our study. One possible explanation is that the expression of the antigens was lost during the development of $\mathrm{EBV}^{+} \mathrm{T}$-cell LPDs after EBV infection. Alternatively, because of loss of many lineage markers for T-cell (CD3, CD4 or CD8), B-cell (CD20) and NK-cell (CD56) of our four cases, we assumed that this disorder is probably derived from other progenitors, for instance, innate lymphoid cells (ILCs). ILCs constitute a recently identified family of mononuclear hematopoietic cells with key functions in maintaining epithelial integrity and tissue immunity throughout the body [17]. They are defined by their lymphoid morphology and the absence of rearranged antigen-specific receptors and lineage markers [18]. Lymphocytes of our four cases were all $\mathrm{CD} 27^{+}$(data not shown) and $\mathrm{CD}^{-} 6^{-}$which prompted a possibility of ILC progenitor. But positivity of other $\mathrm{T}$ cell markers excluded this possibility.

Concerning the differential diagnosis, as one case was catergorized as A3 which was monomorphic LPD with clonal proliferation of EBV-infected cells, the differential diagnosis of T-cell and NK-cell lymphoma was raised. It is clear that some $\mathrm{EBV}^{+} \mathrm{T} / \mathrm{NK}-\mathrm{LPD}$ cases are positive for CD56, cytotoxic molecules and EBER, which is phenotypically identical to that of extranodal NK/T-cell lymphoma, nasal type. Differentiation from these lymphomas is particularly difficult or even impossible in some cases of $\mathrm{EBV}^{+} \mathrm{T} / \mathrm{NK}-\mathrm{LPD}$ because of their secondary development to those well defined lymphomas during the clinical process [12]. We emphasize that the diagnosis of $\mathrm{EBV}^{+} \mathrm{T} / \mathrm{NK}-\mathrm{LPD}$ must be made on the basis of comprehensive considering of typical clinical symptoms and signs, laboratory findings and pathological features. Further studies are required to elucidate its nature and the relationship with T-cell and NK-cell lymphomas. There are controversies about the nature of $\mathrm{EBV}^{+} \mathrm{T} / \mathrm{NK}-\mathrm{LPDs}$ at present. Is it a particular indolent form of T-cell or NK-cell malignancy with a tendency to evolve into a more aggressive neoplasm or a benign or borderline condition with a high risk of evolution into a cytotoxic T-cell or NK-cell lymphoma? We favor the latter because of the fact that this disease displays a wide spectrum of clinical and histopathological features from reactive appearance to overt lymphoma [8] [12].

As for the prognosis of our cases, two of the patients refused to receive further treatment and died one year after initial presentation, one died of postoperative 
complication after surgical resection of the intestinal lesions, and the other one received chemotherapy and remained in stable disease for six months. Kimura $\mathrm{H}$ et al. [19] suggested age at onset of disease ( $\geq 8$ years) and liver dysfunction were risk factors for mortality of patients with $\mathrm{EBV}^{+} \mathrm{T} / \mathrm{NK}-\mathrm{LPD}$. However, no statistical difference was found in survival rate among the issues of $T C R$ rearrangement, EBV monoclonality and chromosomal aberration. Our cases may be in line with the research conclusion that onset age of disease is associated with prognosis whereas $T C R$ gene rearrangement has nothing to do with. Considering the dismal outcomes of $\mathrm{EBV}^{+} \mathrm{T} / \mathrm{NK}-\mathrm{LPDs}$ therapy by using antiviral agents [20] and immunoregulatory drugs such as IFN- $\alpha$ [21], IL-2 [22] and vidarabine [23] partly on account of the attenuated antigen presentation of EBV-infected T or NK cells [24] and impaired CTL activity [25], allogeneic hematopoietic stem cell transplantation (HSCT) appears to be a promising treatment [26].

In summary, we report four cases of $\mathrm{EBV}^{+} \mathrm{T}$-cell LPDs in adolescents and young adults with unusual histopathological and immunophentypic features including multiple foci of necrosis, numerous eosinophils inflitration and granuloma in addition to negativity for CD4 and CD8 of atypical lymphocytes. It is important to recognize these unusual immunophenotypic and histopathologic features of this rare complicated disease. We emphasize the comprehensive considering of clinic symptoms and signs, typical laboratory findings, immunophenotypic and histopathological features in reaching a correct diagnosis. Further studies are needed to clarify the nature of this rare disease and relationship with T-cell and NK-cell lymphomas and facilitate the development of effective treatments.

\section{References}

[1] Cohen, J.I. (2000) Epstein-Barr Virus Infection. The New England Journal of Medicine, 343, 481-492. https://doi.org/10.1056/NEJM200008173430707

[2] Rickinson, A.B., Lee, S.P. and Steven, N.M. (1996) Cytotoxic T Lymphocyte Responses to Epstein-Barr Virus. Current Opinion in Immunology, 8, 492-497. https://doi.org/10.1016/S0952-7915(96)80036-7

[3] Virelizier, J.L., Lenoir, G. and Griscelli, C. (1978) Persistent Epstein-Barr Virus Infection in a Child with Hypergammaglobulinaemia and Immunoblastic Proliferation Associated with a Selective Defect in Immune Interferon Secretion. The Lancet, 2, 231-234. https://doi.org/10.1016/S0140-6736(78)91744-0

[4] Straus, S.E. (1988) The Chronic Mononucleosis Syndrome. The Journal of Infectious Diseases, 157, 405-412. https://doi.org/10.1093/infdis/157.3.405

[5] Kimura, H., et al. (2001) Clinical and Virologic Characteristics of Chronic Active Epstein-Barr Virus Infection. Blood, 98, 280-286.

https://doi.org/10.1182/blood.V98.2.280

[6] Cohen, J.I., et al. (2011) Characterization and Treatment of Chronic Active Epstein-Barr Virus Disease: A 28-Year Experience in the United States. Blood, 117, 5835-5849. https://doi.org/10.1182/blood-2010-11-316745

[7] Ishihara, S., et al. (1997) Clonal Lymphoproliferation Following Chronic Active Epstein-Barr Virus Infection and Hypersensitivity to Mosquito Bites. American Journal of Hematology, 54, 276-281.

https://doi.org/10.1002/(SICI)1096-8652(199704)54:4<276::AID-AJH3>3.0.CO;2-S 
[8] Suzuki, K., et al. (2004) Clinicopathological States of Epstein-Barr Virus-Associated T/NK-Cell Lymphoproliferative Disorders (Severe Chronic Active EBV Infection) of Children and Young Adults. International Journal of Oncology, 24, 1165-1174. https://doi.org/10.3892/ijo.24.5.1165

[9] Swerdlow, S.H., Campo, E., Harris, N.L., et al. (2008) WHO Classification of Tumours of Haematopoietic and Lymphoid Tissues. 4th Edition, IARC Press, Lyon.

[10] Kimura, H. (2006) Pathogenesis of Chronic Active Epstein-Barr Virus Infection: Is this an Infectious Disease, Lymphoproliferative Disorder, or Immunodeficiency? Reviews in Medical Virology, 16, 251-261. https://doi.org/10.1002/rmv.505

[11] Okano, M., et al. (2005) Proposed Guidelines for Diagnosing Chronic Active Epstein-Barr Virus Infection. American Journal of Hematology, 80, 64-69. https://doi.org/10.1002/ajh.20398

[12] Ohshima, K., et al. (2008) Proposed Categorization of Pathological States of EBV-Associated T/Natural Killer-Cell Lymphoproliferative Disorder (LPD) in Children and Young Adults: Overlap with Chronic Active EBV Infection and Infantile Fulminant EBV T-LPD. Pathology International, 58, 209-217.

https://doi.org/10.1111/j.1440-1827.2008.02213.x

[13] Van Dongen, J.J., et al. (2003) Design and Standardization of PCR Primers and Protocols for Detection of Clonal Immunoglobulin and T-Cell Receptor Gene Recombinations in Suspect Lymphoproliferations: Report of the BIOMED-2 Concerted Action BMH4-CT98-3936. Leukemia, 17, 2257-2317. https://doi.org/10.1038/sj.leu.2403202

[14] Su, I.J., et al. (1990) Fatal Primary Epstein-Barr Virus Infection Masquerading as Histiocytic Medullary Reticulosis in Young Children in Taiwan. Hematologic Pathology, 4, 189-195.

[15] Cohen, J.I., et al. (2009) Epstein-Barr Virus-Associated Lymphoproliferative Disease in Non-Immunocompromised Hosts: A Status Report and Summary of an International Meeting, 8-9 September 2008. Annals of Oncology, 20, 1472-1482. https://doi.org/10.1093/annonc/mdp064

[16] Kimura, H., et al. (2003) Prognostic Factors for Chronic Active Epstein-Barr Virus Infection. The Journal of Infectious Diseases, 187, 527-533. https://doi.org/10.1086/367988

[17] Spits, H. and Cupedo, T. (2012) Innate Lymphoid Cells: Emerging Insights in Development, Lineage Relationships, and Function. Annual Review of Immunology, 30, 647-675. https://doi.org/10.1146/annurev-immunol-020711-075053

[18] Hazenberg, M.D. and Spits, H. (2014) Human Innate Lymphoid Cells. Blood, 124, 700-709. https://doi.org/10.1182/blood-2013-11-427781

[19] Kimura, H., et al. (2012) EBV-Associated T/NK-Cell Lymphoproliferative Diseases in Nonimmunocompromised Hosts: Prospective Analysis of 108 Cases. Blood, 119, 673-686. https://doi.org/10.1182/blood-2011-10-381921

[20] Schooley, R.T., Miller, G., Henle, W., Eastman, R., Mark, E.J., Kenyon, K., Wheeler, E.O. and Rubin, R.H. (1986) Chronic Epstein-Barr Virus Infection Associated with Fever and Interstitial Pneumonitis. Clinical and Serologic Features and Response to Antiviral Chemotherapy. Annals of Internal Medicine, 104, 636-643. https://doi.org/10.7326/0003-4819-104-5-636

[21] Sakai, Y., et al. (1998) Interferon-Alpha Therapy for Chronic Active Epstein-Barr Virus Infection: Potential Effect on the Development of T-Lymphoproliferative Disease. Journal of Pediatric Hematology/ Oncology, 20, 342-346. https://doi.org/10.1097/00043426-199807000-00013 
[22] Kawa-Ha, K., et al. (1987) Successful Treatment of Chronic Active Epstein-Barr Virus Infection with Recombinant Interleukin-2. The Lancet, 1, 154.

[23] Kimura, H., et al. (2001) Vidarabine Therapy for Severe Chronic Active Epstein-Barr Virus Infection. Journal of Pediatric Hematology/ Oncology, 23, 294-299. https://doi.org/10.1097/00043426-200106000-00012

[24] Kimura, H.T.I., Imai, S., Yamamoto, M., Kuzushima, K., Osato, T. and Morishima, T. (1995) Intact Antigen Presentation for Epstein-Barr Virus (EBV)-Specific CTL by a Lymphoblastoid Cell Line Established from a Patient with Severe Chronic Active EBV Infection. Medical Microbiology and Immunology, 184, 63-68. https://doi.org/10.1007/BF00221388

[25] Tsuge, I., et al. (2001) Impaired Cytotoxic T Lymphocyte Response to Epstein-Barr Virus-Infected NK Cells in Patients with Severe Chronic Active EBV Infection. Journal of Medical Virology, 64, 141-148. https://doi.org/10.1002/jmv.1029

[26] Kawa, K., et al. (2011) Excellent Outcome of Allogeneic Hematopoietic SCT with Reduced-Intensity Conditioning for the Treatment of Chronic Active EBV Infection. Bone Marrow Transplant, 46, 77-83. https://doi.org/10.1038/bmt.2010.122

Submit or recommend next manuscript to OALib Journal and we will provide best service for you:

- Publication frequency: Monthly

- 9 subject areas of science, technology and medicine

- Fair and rigorous peer-review system

- Fast publication process

- Article promotion in various social networking sites (LinkedIn, Facebook, Twitter, etc.)

- Maximum dissemination of your research work

Submit Your Paper Online: Click Here to Submit

Or Contact service@oalib.com 